\title{
Preparation of Radioactive Waste to Long Storage (Burial) Using of the Cement Compound
}

\author{
Tatiana A. Kulagina*a and Vladislav A. Popkov ${ }^{a, b}$ \\ a Siberian Federal University \\ 79 Svobodny, Krasnoyarsk, 660041, Russia \\ ${ }^{b}$ Radiochemical plant Mining and Chemical Combine \\ 53 Lenin Str., Zheleznogorsk, 662970, Russia
}

Received 11.05.2015, received in revised form 08.07.2015, accepted 24.09.2015

\begin{abstract}
In the article presents the results of investigations of the processes solidify liquid of radioactive waste low and intermediate level to inorganic astringent (cementation process). Formed by cementing the product has a number of advantages: high mechanical strength, is not combustible, radiation and chemically stable, low external radiation cementations materials due to the high density. Cementing of technology as conditioning of liquid radioactive waste is a process of immobilization of liquid radioactive waste to cement matrix to obtain a solid final product (cement compound). Substantiated the use of of effects cavitational technology, quite easy to implement, energy efficient and in some cases having no alternative. Disposal of waste radiochemical production during the decommissioning of nuclear power plants on the basis of impulse cavitational technology increases the strength the cement compound.
\end{abstract}

Keywords: cement compound, cavitational technology, the decommissioning of nuclear power plants.

DOI: 10.17516/1999-494X-2015-8-7-917-927.

(C) Siberian Federal University. All rights reserved

* Corresponding author E-mail address: tak.sfu@gmail.com 


\title{
Подготовка радиоактивных отходов \\ к длительному хранению (захоронению) \\ с помощью цементных компаундов
}

\author{
Т.А. Кулагина ${ }^{a}$, В.А. Попков ${ }^{\text {a, }}$ \\ аСибирский федеральный университет \\ Россия, 660041, Красноярск, Свободный, 79 \\ бРадиохимический завод Горно-химического комбината \\ Россия, 662970, Железногорск, Ленина, 53
}

Изложены результать исследований процессов отверждения жидких радиоактивных отходов низкого и среднего уровней активности в неорганические вяжущче (процесс иементирования). Образуюшийся при ичементировании продукт обладает ичельм рядом достоинств: высокая механическая прочность, негорюч, радиационно и химически устойчив, пониженное внешнее излучение цементных материалов из-за высокой плотности. Цементирование как технология кондиционирования жидких радиоактивных отходов представляет собой процесс иммобилизации жидких радиоактивных отходов в ијементную матрииу с получением твёрдого конечного продукта (цементного компаунда). Показана целесообразность использования эффектов кавитационной технологии, достаточно легко реализуемой, энергоэффективной и в ряде случаев не имеющей альтернативы. Утилизация отходов радиохимического производства при выводе из эксплуатациии ядерных энергетических установок на базе кавитационной технологии приводит к повычению прочности цементного компаунда.

Ключевые слова: цементный компаунд, кавитаџионная технология, вывод из эксплуатаџии ядерных энергетических установок.

\section{Введение}

В соответствии с Международной конвенцией о безопасности обращения с радиоактивными отходами на всех его этапах должны быть обеспечены эффективные средства защиты отдельных лиц, общества в целом и окружающей среды от вредного воздействия радионуклидов и ионизирующего излучения как в настоящее время, так и в будущем. С точки зрения долговременной безопасности наиболее важным этапом обращения с радиоактивными отходами является их длительное хранение и захоронение [1-3].

Одним из факторов, обеспечивающих безопасность длительного хранения и захоронения радиоактивных отходов, является их физико-химическая характеристика. При выборе формы захораниваемых отходов следует учитывать не только соответствие ее качества действующим нормативным требованиям, но и экономические факторы [3-7].

Наиболее широко используемым в настоящее время процессом отверждения жидких радиоактивных отходов (ЖРО) низкого и среднего уровней активности служит включение их в неорганические вяжущие (процесс цементирования) [8]. Образующийся при цементировании продукт обладает целым рядом достоинств: высокая механическая прочность, негорюч, радиационно и химически устойчив. Высокая плотность цементных материалов способствует уменьшению внешнего излучения $[9,10]$.

В рамках данных исследований специалистами ФГАОУ ВПО «Сибирский федеральный университет» и Радиохимического завода ФГУП «Горно-химический комбинат» (г. Железно- 
горск) проведены работы по обработке радиоактивной пульпы ультразвуком для изменения гранулометрического состава и ее отверждение в виде цементного компаунда с использованием технической воды и обработанной воды с использованием эффектов кавитации.

\section{Результаты экспериментальных исследований}

Ультразвуковая обработка пульпы. Однородность и равномерность распределения радиоактивных отходов (РАО) в структуре компаунда выступает одним из важных требований к характеристикам отверждённых РАО (НП-019-2000 «Сбор, переработка, хранение и кондиционирование жидких радиоактивных отходов. Требования безопасности». М., 2000, п. 3.4.2.4).

Для уменьшения радиуса частиц пульпы и получения более однородного состава компаунда пульпу обрабатывали с помощью ультразвукового генератора (табл. 1) - шесть циклов по 10 минут с перерывом 10 минут (рис. 1).

Снижение размерности частиц РАО позволяет достигнуть более равномерного их распределения в структуре компаунда. На стадии смешения цементного раствора мелкие частицы

Таблица 1. Технические характеристики ультразвукового генератора

\begin{tabular}{|c|l|c|c|}
\hline № п/п Наименование характеристики & Размерность & Показатель \\
\hline 1 & Мощность выходная, максимальная & Вт & $60 \pm 10$ \\
\hline 2 & Пределы плавной регулировки выходной мощности & Вт & $10-60$ \\
\hline 3 & Рабочая частота & кГц & $22 \pm 1,63$ \\
\hline 4 & Мощность, потребляемая от сети, не более & кВА & 0,2 \\
\hline 5 & Напряжение однофазной питающей сети & В & $220 \pm 5$ \\
\hline 6 & Частота питающей сети & Гц & 50 \\
\hline 7 & Масса, не более & кг & 11 \\
\hline 8 & Габаритные размеры, не более & мм & $310 * 350 * 150$ \\
\hline
\end{tabular}

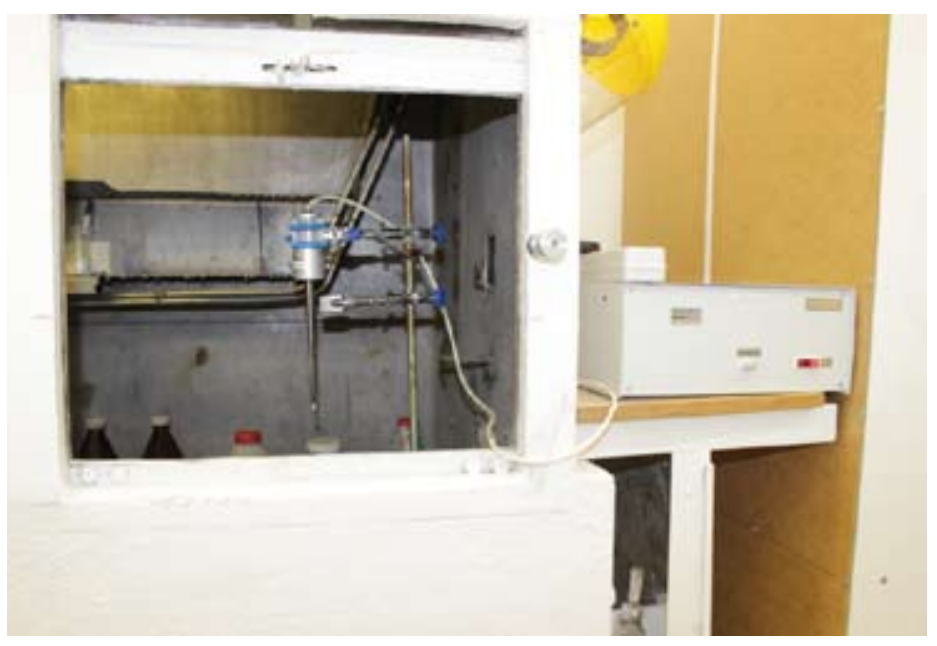

Рис. 1. Ультразвуковой генератор УЗД1-0,063/22 
РАО, обладающие более низкой скоростью седиментации, не успевают оседать под действием силы тяжести и сконцентрироваться в придонной зоне. Ультразвуковой диспергатор УЗД10,063/22 предназначен для создания в жидкостях интенсивной зоны кавитации и состоит из ультразвукового генератора, выполняющего роль источника питания, и ультразвукового пьезокерамического преобразователя электрической энергии в энергию механических ультразвуковых колебаний рабочего инструмента.

Для определения размера частиц применяли седиментационный метод, основанный на зависимости размеров частиц от скорости их оседания, выражающийся уравнениями

$$
\begin{aligned}
& r=\sqrt{\frac{9 U \mu}{2(D-\rho) g}}, \\
& r=K \sqrt{U} \\
& K=\sqrt{\frac{9 \mu}{2(D-\rho) g}},
\end{aligned}
$$

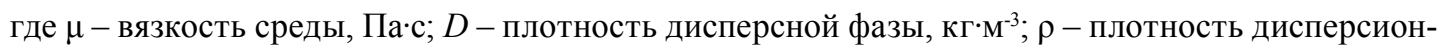

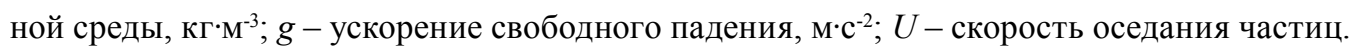

$$
U=\frac{H}{\tau},
$$

где Н - высота оседания частиц, м; $\tau$ - время оседания, с.

Определив экспериментально эти величины и рассчитав константу $K$, можно вычислить эквивалентные радиусы частиц, оседающих за те или иные промежутки времени. Для проведения седиментационного анализа дисперсной системы пользуются торсионными весами. Результаты седиментационного анализа показывают, что с увеличением количества циклов обработки пульпы ультразвуком уменьшается радиус частиц пульпы. Так, согласно дифференциальным кривым распределения, если в исходной пульпе больше частиц с радиусом 50 мкм, то после двух циклов обработки пульпы ультразвуком преобладают частицы радиусом 20 мкм. После четырех циклов обработки пульпы ультразвуком практически все частицы стали с радиусом 20 мкм. А после шести циклов обработки пульпы ультразвуком преобладают частицы с радиусом до 10 мкм.

Приготовление компаунда. В соответствии с программой проведения экспериментальных работ по выбору состава цементного компаунда и технологических режимов цементирования для приготовления цементного компаунда использовали:

портландцемент марки ЦЕМ I 42,5Б, ГОСТ 31108-2003 (по прежней классификации ПЦ 500-Д0), ОАО «Мордовцемент»;

сорбционную добавку - молотый клиноптилолит Холинского месторождения ТУ 2163-002-12763074 следующего фракционного состава ( \% по массе): более 1 мм - 2,55; до 0,5 мм - 13,74; до 0,25 мм - 12,20; до 0,125 мм - 34,19; до 0,1 мм - 15,23; до 0,05 мм - 20,03; менее 0,05 мм - 2,06;

техническую воду и воду после кавитационного воздействия (табл. 2);

нерастворимые остатки гидроксидной пульпы.

$$
-920-
$$


Таблица 2. Характеристика используемой воды

\begin{tabular}{|c|c|c|}
\hline \multirow{2}{*}{ Образец воды } & \multicolumn{2}{|c|}{ Значение показателя } \\
\cline { 2 - 3 } & $\mathrm{pH}$ & солесодержание, мг/л \\
\hline Техническая вода & 7,5 & 310 \\
\hline Образец № 1 & 7,8 & 3,01 \\
\hline Образец № 2 & 7,7 & 2,64 \\
\hline Образец № 3 & 7,6 & 0,65 \\
\hline
\end{tabular}

Обработка воды (образцы 1, 2) проводилась в гидродинамическом суперкавитационном реакторе [11]. Образец № 1 - дистиллированная вода, скорость вращения ротора 10 тыс. об/мин, время обработки 5 мин. Образец № 2 - дистиллированная вода, скорость вращения ротора 10 тыс. об/мин, время обработки 3 мин. Образец № 3 - дистиллированная вода.

Состав цементного раствора корректировался после проведения пробного замеса с использованием приобретенных для проведения опытных операций вяжущих компонентов и определения растекаемости цементного раствора. Для определения растекаемости цементного компаунда использовали прибор Суттарда по ГОСТ 23789-79 «Вяжущие гипсовые. Методы испытаний». Прибор Суттарда с малым вискозиметром, применяемый для определения растекаемости, состоит из латунного цилиндра, имеющего внутренний диаметр 40 мм и высоту 80 мм, и квадратного листового стекла, размер сторон которого 260 мм.

Образец цементного компаунда после его приготовления заливали в цилиндр, установленный на ровную горизонтальную поверхность в центре стекла, поверхность раствора выравнивали с краями цилиндра. Потом резким движением поднимали цилиндр снизу вверх. При этом цементный компаунд разливался на стекле в лепешку. Растекаемость определяли с помощью линейки как среднее арифметическое двух измерений. Регламентированная растекаемость изолирующего материала 190х200 мм.

При изготовлении образцов использовали следующую схему смешивания компонентов: клиноптилолит с гидроксидной пульпой загружали в пластиковые стаканы в заданных соотношениях и перемешивали. Через 15 мин добавляли расчетное количество цемента и воды и смесь тщательно перемешивали. Полученную смесь вносили в специально изготовленные формы из фторопласта для формирования образцов диаметром и высотой по 20 мм (рис. 2). Путем легкого постукивания по корпусу форм в течение нескольких минут смесь уплотняли и удаляли из нее воздух.

Затем формы с образцами помещали на 24 ч в камеру нормального твердения, обеспечивающую при температуре $(20 \pm 3){ }^{\circ} \mathrm{C}$ относительную влажность воздуха $(95 \pm 5) \%$. Через сутки образцы извлекали из форм и помещали их обратно в камеру нормального твердения (рис. 3) на 28 суток. После выдержки образцы испытывали на механическую прочность, водо- и морозостойкость по трем образцам для обеспечения сопоставимости результатов.

Испытания на механическую прочность. Механическую прочность образцов определяли по отраслевой инструкции «Цементные компаунды на основе радиоактивных отходов. Определение предела прочности на сжатие на испытательной машине марки TESTING ОИ 001.725-2011». Измерение предела прочности цементных компаундов основано на вы- 


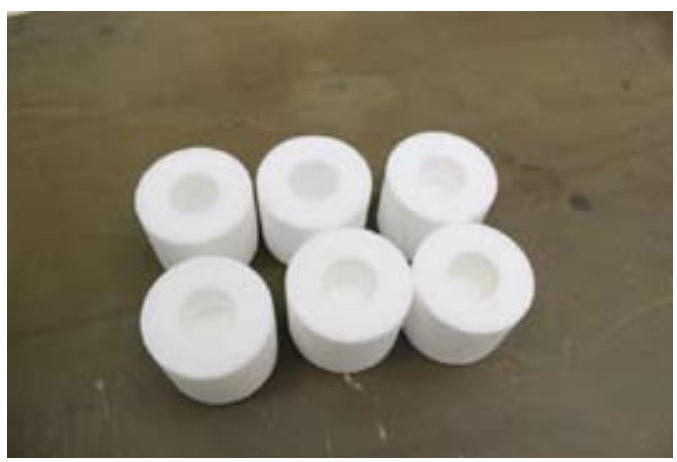

Рис. 2. Вид фторопластовых форм для отливки образцов

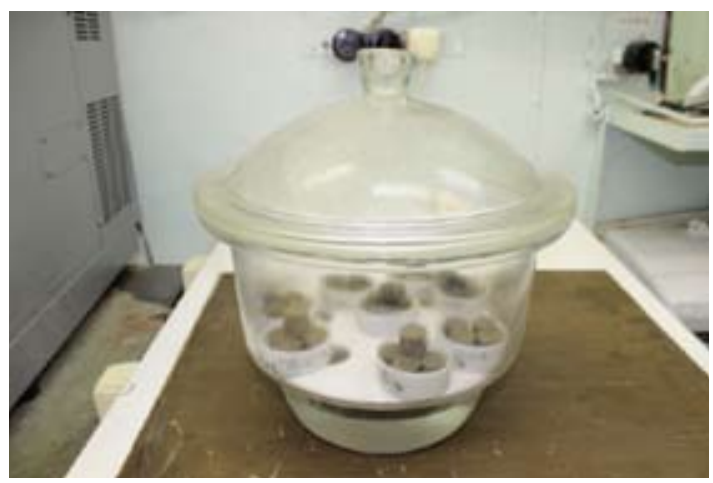

Рис. 3. Камера нормального твердения

явлении максимальной нагрузки, которую образец выдерживает, не разрушаясь. При измерении предела прочности исследуемый образец с определенной площадью поверхности подвергался постепенной и равномерной нагрузке (сила $F, \kappa \mathrm{H})$, величина которой отображается на пульте оператора. В момент разрушения образца значение силы $F$ резко падает. Последнее максимальное значение силы $F$ перед снижением величины считается пределом прочности данного образца. Результат измерений прочности, рассчитанный автоматически испытательной машиной на основании введенных данных о площади поверхности данного образца и измеренной максимальной силе нагрузки, представляется на пульте оператора в МПа.

Механические испытания на сжатие (ГОСТ 310.4) проводили на гидравлическом прессе BM-3,4 (рис. 4) (диапазон производимого усилия 5500 кН, напряжение питания $220 \mathrm{~B}$, мощность 1,0 кВт).

При выполнении измерений соблюдают следующие условия: температура воздуха $(22 \pm 5)^{\circ} \mathrm{C}$; относительная влажность воздуха не более $80 \%$; атмосферное давление от 84,0 до 106,7 кПа. Результаты механических испытаний отражены в табл. 3.

Испытания на морозостойкость. Испытания на морозостойкость проводили по отраслевой инструкции «Цементные компаунды. Определение морозостойкости. Методика проведения испытаний ОИ 001.730-2011» (ГОСТ 10060-2012). Методика испытаний предназначена для 


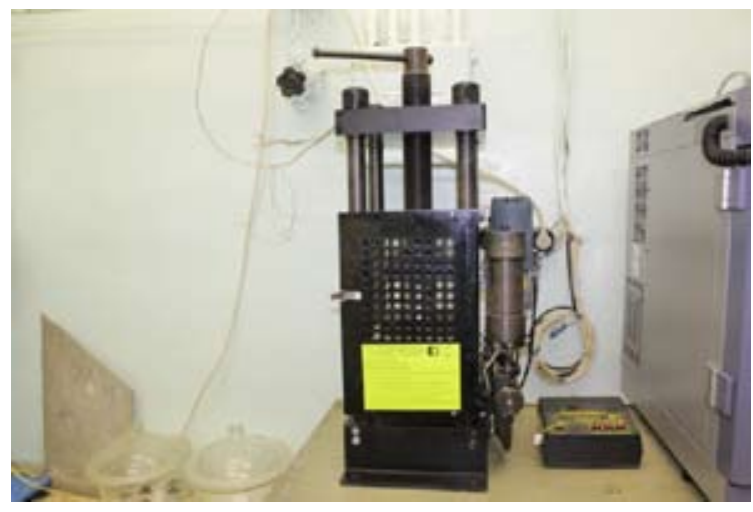

Рис. 4. Общий вид гидравлического пресса ВМ-3,4

Таблица 3. Исходная механическая прочность цементных компаундов

\begin{tabular}{|c|c|c|c|c|c|c|c|c|c|}
\hline \multicolumn{2}{|c|}{ Показатель } & \multicolumn{8}{|c|}{ Механическая прочность компаунда через 28 суток, МПа } \\
\hline В/Ц & $\mathrm{B} / \mathrm{B}$ & \multicolumn{2}{|c|}{ с техн. водой } & \multicolumn{2}{|c|}{$\begin{array}{c}\text { с водой образца } \\
\text { № } 1\end{array}$} & \multicolumn{2}{|c|}{$\begin{array}{c}\text { с водой образца } \\
\text { № } 2\end{array}$} & \multicolumn{2}{|c|}{$\begin{array}{c}\text { с водой образца } \\
\text { № } 4\end{array}$} \\
\hline \multirow{2}{*}{0.5} & \multirow{2}{*}{0.41} & 36,0 & 32,5 & 27,4 & 27,7 & 39,2 & 45,2 & 52,2 & 43,0 \\
\hline & & \multicolumn{2}{|c|}{ среднее 34,2} & \multicolumn{2}{|c|}{ среднее 27,5} & \multicolumn{2}{|c|}{ среднее 42,2} & \multicolumn{2}{|c|}{ среднее 47,6} \\
\hline
\end{tabular}

Примечание: В/Ц - отношение массы воды в компаунде к массе цемента, использованного на приготовление компаунда. В/В - отношение массы воды в компаунде к массе вяжущих компонентов компаунда (в данном случае «цемент + клиноптилолит»).

определения морозостойкости цементных компаундов, в том числе содержащих радиоактивные отходы. В условиях длительного хранения цементная матрица может быть подвержена совместному воздействию знакопеременных температур и водной среды. Для оценки качества цементных компаундов необходимо сравнение прочности на сжатие образцов, подвергнутых переменному замораживанию и оттаиванию, и контрольных образцов в эквивалентном возрасте твердения.

Под морозостойкостью понимают способность цементных компаундов сохранять физикомеханические свойства (прочность на сжатие) при многократном переменном замораживании и оттаивании. Согласно требованиям ГОСТ Р 51883-2002 цементные компаунды считаются морозостойкими, если их прочность на сжатие после испытаний составляет не менее 5 МПа. Данная методика разработана на основе базового метода определения морозостойкости по ГОСТ 10060.0-95 - ГОСТ 10060.1-95.

Морозостойкость устанавливали путем сравнения механической прочности образцов, прошедших 30 циклов попеременного замораживания и оттаивания, с их исходной прочностью. Морозостойкость компаунда считается удовлетворительной, если прочность образцов, прошедших испытания, составляет не менее 75 \% от исходной прочности (но не ниже допустимых 5 МПа). Для определения морозостойкости использовали шкаф холодильный типа «Ларь» (рис. 5) ШН(L)Y-0,175 «Бирюса-200К-5» (температура полезного объема не выше минус $18{ }^{\circ} \mathrm{C}$, напряжение питания 220 В, мощность 150 Вт).

$$
-923-
$$




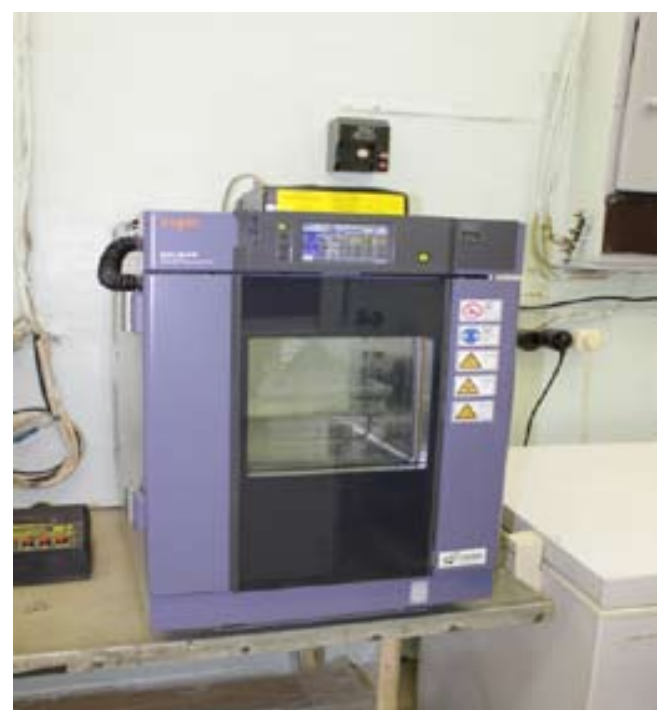

Рис. 5. Фото холодильного шкафа

Таблица 4. Результаты испытаний образца цементного компаунда

\begin{tabular}{|c|c|c|c|c|c|}
\hline $\begin{array}{c}\text { № } \\
\text { образца }\end{array}$ & $\begin{array}{c}\text { Механическая } \\
\text { прочность, } \\
\text { МПа }\end{array}$ & $\begin{array}{c}\text { Среднее } \\
\text { значение, } \\
\text { МПа }\end{array}$ & $\begin{array}{c}\text { Морозостойкость, } \\
\text { МПа }\end{array}$ & $\begin{array}{c}\text { Среднее } \\
\text { значение, } \\
\text { МПа }\end{array}$ & $\begin{array}{c}\text { Изменение } \\
\text { механической } \\
\text { прочности после } \\
\text { морозостойкости, \% }\end{array}$ \\
\hline $1-1$ & 36,0 & \multirow{2}{*}{34,2} & 32,8 & \multirow{2}{*}{29,8} & \multirow{2}{*}{$-12,9$} \\
\hline $1-2$ & 32,5 & & 26,8 & & \\
\hline $2-1$ & 27,4 & \multirow{2}{*}{27,5} & 21,3 & \multirow{2}{*}{21,6} & \multirow{2}{*}{$-21,5$} \\
\hline $2-2$ & 27,7 & & 22,0 & & \\
\hline $3-1$ & 39,2 & \multirow{2}{*}{42,2} & 50,7 & \multirow{2}{*}{42,4} & \multirow{2}{*}{0,5} \\
\hline $3-2$ & 45,2 & & 34,1 & & \\
\hline $4-1$ & 52,2 & \multirow{2}{*}{47,6} & 52,9 & \multirow{2}{*}{48,4} & \multirow{2}{*}{1,7} \\
\hline $4-2$ & 43,0 & & 44,0 & & \\
\hline
\end{tabular}

Образцы цементного компаунда помещали в сетчатый контейнер. Контейнер погружали в ванну с дистиллированной водой при температуре $(20 \pm 2){ }^{\circ} \mathrm{C}$. Через 96 ч контейнер извлекали из ванны, помещали в морозильную камеру и выдерживали в ней при температуре минус $18{ }^{\circ} \mathrm{C}$ в течение 2 ч. После выдержки в морозильной камере образцы извлекали и помещали в вытяжной шкаф на 2 ч. После оттаивания образцы визуально осматривали и фиксировали изменения. Испытания повторяли 30 циклов. Результаты представлены в табл. 4.

Определение скорости выщелачивания. Одним из основных факторов, определяющих надежность длительного хранения и захоронения радиоактивных отходов, является скорость выщелачивания радионуклидов. Согласно ГОСТ Р 51883-2002 скорость выщелачивания радионуклидов (цезия-137 и стронция-90) из цементной матрицы не должна превышать $1 \cdot 10^{-3} \Gamma /\left(\mathrm{cm}^{2}\right.$.сут.). 
В связи с отсутствием в составе пульпы значимого количества стронция-90 и технической сложностью его определения скорость выщелачивания устанавливали по цезию-137. Определение скорости выщелачивания проводили по ГОСТ Р 52126-2003. Подготовленные образцы извлекали из камеры нормального твердения, помещали в пластиковые стаканы и заливали 50 мл дистиллированной воды (рис. 6). Отношение объема контактного раствора к поверхности образца составляло 2,65. Стаканчики закрывали крышками для предотвращения испарения воды и оставляли в вытяжном шкафу.

Через $1,3,7,10,14,21,28$ и 56 суток контактный раствор сливали и направляли на анализ, а образцы заливали новой порцией дистиллированной воды. В контактной воде определяли концентрацию цезия-137 по методикам, принятым в ФГУП «ГХК». Испытания проводили до установления постоянного значения скорости выщелачивания, которое рассчитывают по формуле

$$
R_{n}=\frac{a_{n}}{A_{0} \cdot S \cdot \tau_{n}}
$$

где $R_{n}$ - скорость выщелачивания цезия-137, г/(см².сутки); $a_{n}$ - активность цезия-137, перешедшего в воду за время $\tau_{n}$, Бк; $A_{0}$ - удельная активность цезия-137 в образце, Бк/г; $S$ - площадь открытой геометрической поверхности образца, находящейся в контакте с водой, $\mathrm{cm}^{2} ; \tau_{n}$ - продолжительность n-го периода выщелачивания, сут. Результаты измерения скорости выщелачивания цезия-137 даны в табл. 5.

\section{Обсуждение результатов}

С увеличением количества циклов обработки пульпы ультразвуком уменьшается радиус частиц пульпы. Получаемый компаунд становится более однородным на микроуровне. Радиационная нагрузка по $\beta$ - и $\alpha$-воздействию на твёрдую фазу компаунда более равномерна, что улучшает радиационную устойчивость отверждённых РАО. Наилучшая механическая прочность и морозостойкость компаундов через 28 сут была у образцов, приготовленных с использованием кавитационно обработанной воды (образцы № 2 и 4). Все образцы цементных компаундов подтвердили свою надежность по показателю скорости выщелачивания цезия-137.

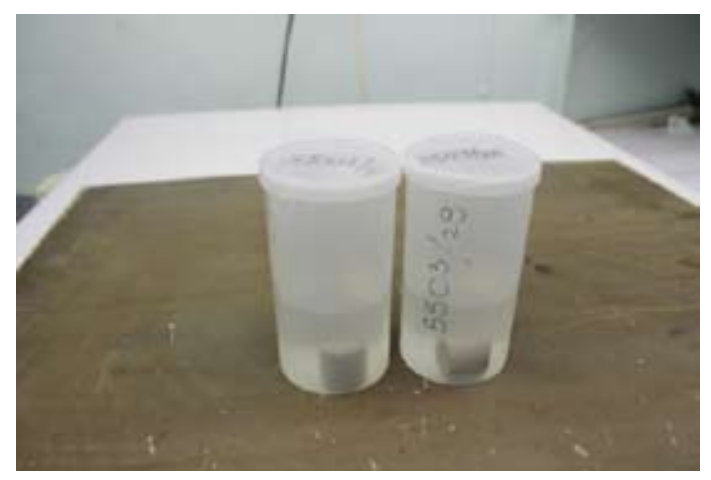

Рис. 6. Образцы, выдерживаемые в воде

$$
-925-
$$


Таблица 5. Скорость выщелачивания цезия-137

\begin{tabular}{|c|c|c|c|c|c|c|c|c|c|}
\hline \multirow{2}{*}{$\begin{array}{c}\text { № } \\
\text { образца }\end{array}$} & \multirow{2}{*}{$\begin{array}{c}\text { Удельная } \\
\text { активность } \\
\text { компаунда, Бк/г }\end{array}$} & \multicolumn{8}{|c|}{ Скорость выщелачивания цезия-137, г/(см² ·сут) } \\
\hline & & $\begin{array}{c}1 \\
\text { сутки }\end{array}$ & $\begin{array}{c}3 \\
\text { суток }\end{array}$ & $\begin{array}{c}7 \\
\text { суток }\end{array}$ & $\begin{array}{c}10 \\
\text { суток }\end{array}$ & $\begin{array}{c}14 \\
\text { суток }\end{array}$ & $\begin{array}{c}21 \\
\text { суток }\end{array}$ & $\begin{array}{c}28 \\
\text { суток }\end{array}$ & $\begin{array}{c}56 \\
\text { суток }\end{array}$ \\
\hline $1-1$ & 5850 & $1,03 \mathrm{E}-2$ & $2,47 \mathrm{E}-3$ & $2,93 \mathrm{E}-4$ & $2,00 \mathrm{E}-4$ & $1,88 \mathrm{E}-4$ & $1,26 \mathrm{E}-4$ & $9,46 \mathrm{E}-5$ & $4,89 \mathrm{E}-5$ \\
\hline $1-2$ & 980 & $9,4 \mathrm{E}-2$ & $2,78 \mathrm{E}-2$ & $3,04 \mathrm{E}-4$ & $2,17 \mathrm{E}-4$ & $1,55 \mathrm{E}-4$ & $1,33 \mathrm{E}-4$ & $9,01 \mathrm{E}-5$ & $5,67 \mathrm{E}-5$ \\
\hline $2-1$ & 1840 & $6,12 \mathrm{E}-2$ & $1,51 \mathrm{E}-2$ & $2,01 \mathrm{E}-3$ & $1,13 \mathrm{E}-3$ & $8,08 \mathrm{E}-4$ & $5,77 \mathrm{E}-4$ & $4,95 \mathrm{E}-4$ & $2,52 \mathrm{E}-4$ \\
\hline $2-2$ & 3840 & $6,69 \mathrm{E}-2$ & $3,29 \mathrm{E}-2$ & $1,87 \mathrm{E}-3$ & $1,16 \mathrm{E}-3$ & $8,47 \mathrm{E}-4$ & $5,83 \mathrm{E}-4$ & $5,09 \mathrm{E}-4$ & $2,34 \mathrm{E}-4$ \\
\hline $3-1$ & 2050 & $5,07 \mathrm{E}-2$ & $2,82 \mathrm{E}-2$ & $1,83 \mathrm{E}-3$ & $1,45 \mathrm{E}-3$ & $7,03 \mathrm{E}-4$ & $6,18 \mathrm{E}-4$ & $5,23 \mathrm{E}-4$ & $2,55 \mathrm{E}-4$ \\
\hline $3-2$ & 3150 & $7,95 \mathrm{E}-2$ & $4,36 \mathrm{E}-2$ & $2,16 \mathrm{E}-3$ & $1,67 \mathrm{E}-3$ & $7,31 \mathrm{E}-4$ & $6,62 \mathrm{E}-4$ & $5,18 \mathrm{E}-4$ & $2,71 \mathrm{E}-4$ \\
\hline $4-1$ & 3680 & $7,34 \mathrm{E}-2$ & $3,78 \mathrm{E}-2$ & $2,86 \mathrm{E}-3$ & $1,91 \mathrm{E}-3$ & $1,81 \mathrm{E}-3$ & $7,97 \mathrm{E}-4$ & $6,96 \mathrm{E}-4$ & $3,20 \mathrm{E}-4$ \\
\hline $4-2$ & 1400 & $1,22 \mathrm{E}-1$ & $6,07 \mathrm{E}-2$ & $3,45 \mathrm{E}-3$ & $2,13 \mathrm{E}-3$ & $1,74 \mathrm{E}-3$ & $8,41 \mathrm{E}-4$ & $7,19 \mathrm{E}-4$ & $3,57 \mathrm{E}-4$ \\
\hline
\end{tabular}

\section{Вывод}

Использование кавитационно-активированной воды позволяет достичь долговременной радиационной устойчивости отверждённых РАО и отвечает требованиям федеральных норм и правил $[12,13]$.

\section{Список литературы}

[1] Кулагина Т.А., Козин О.А., Матюшенко А.И. Экологическая безопасность техносферных объектов: монография. Красноярск: Гротеск; СФУ, 2015. 322 с.

[2] Кулагина Т.А. Кулагин В.А., Матюшенко А.И. Техносферная безопасность в ядерной энергетике: учеб. пособие. Красноярск: Гротеск, СФУ, 2014. 286 с.

[3] Кулагина Т.А., Матюшенко А.И., Комонов С.В. и др. Управление промышленными и особо опасными отходами: монография / ред. А. И. Матюшенко. М.: Маджента, 2010. 567 с.

[4] Гарин В.М. Обращение с опасными отходами: учеб. пособие / ред. В.М. Гарин, Г.Н. Соколова. М.: ТК «Велби»; Проспект, 2006. 224 с.

[5] Лебедев В.М. Ядерный топливный цикл. М.: Энергоатомиздат, 2005. 305 с.

[6] Nuclear Waste: Challenges to Achieving Potential Savings in DOE's High-Level Waste Cleanup Program // United States General Accounting Office, Report to the Chairman, Subcommittee on Oversight and Investigations, Committee on Energy and Commerce, House of Representatives. GAO-03-593, June 2003. P. 17, 20.

[7] Гутенев В.В., Кулагина Т.А. , Русак О.Н. и др. Экология техносферы: учеб. пособие для вузов / ред. Т.А. Кулагина. М.: Маджента, 2008. 468 с.

[8] Кулагина Т.А., Попков В.А. // Журнал СФУ. Техника и технологии. 2015 (8). № 2. 194-204

[9] Кулагина Т.А., Попков В.А. // Журнал СФУ. Техника и технологии. 2015 (8). № 3. 362-368.

[10] Кулагина T.A., Попков В.А. // Сложные системы в экстремальных условиях: Тез. докладов XVII Всерос. симпоз. с международным участием. Красноярск: КНЦ СО РАН, 2014. С. 35.

[11] Ивченко В.М., Кулагин В.А., Немчин А.Ф. Кавитационная технология; ред. Г.В. Логвинович. Красноярск: Изд-во КГУ, 1990. 200 с.

[12] Ли Ф.М. Химия цемента и бетона. М., 1961.

$$
-926-
$$


[13] Суханов Л.П., Черников М.А. Оценка соответствия качества цементного компаунда требованиям нормативных документов, определение допустимой степени включения плутонийсодержащего нерастворимого остатка в цементный компаунд // Отчет ВНИИНМ. Инв. № 10989, 2006. 